\title{
EFEITO DO SILÍCIO NA INTENSIDADE DA CERCOSPORIOSE E NA NUTRIÇÃO MINERAL DE MUDAS DE CAFEEIRO
}

\author{
D.M.S. Botelho ${ }^{1}$, E.A. Pozza ${ }^{2}$, E. Alves ${ }^{2}$, C.E. Botelho ${ }^{1}$, \\ A.A.A. Pozza ${ }^{3}$, P.M. Ribeiro Júnior ${ }^{2}$, P.E. de Souza ${ }^{2}$ \\ ${ }^{1}$ Empresa de Pesquisa Agropecuária de Minas Gerais, Centro Tecnológico do Sul de Minas, CP 176, CEP \\ 37200-000, Lavras, MG, Brasil. E-mail: deilamagna@hotmail.com
}

\section{RESUMO}

O presente trabalho objetivou estudar o efeito do silício na intensidade da cercosporiose e na nutrição mineral de mudas de cafeeiro. No experimento 1 , testou-se seis doses de ácido silícico $(0$, 0,$5 ; 1 ; 2 ; 4$ e $6 \mathrm{~g} \mathrm{~kg}^{-1}$ de solo) em mudas da cultivar Catuaí Vermelho IAC 99 inoculadas com o fungo Cercospora coffeicola. No experimento 2, foram realizadas microanálises de raios-X para a avaliação de nutrientes presentes nas folhas das mudas de cafeeiro das cultivares Topázio MG1190 e Icatu Precoce IAC 3282, inoculadas e não inoculadas com C. coffeicola, com e sem silicato de cálcio (1 g $\mathrm{kg}^{-1}$ de solo). Com o aumento das doses de ácido silícico observou-se redução na área abaixo da curva de progresso do número de lesões por folha (AACPNLF), redução linear nos teores foliares de magnésio e fósforo e aumento nos teores de enxofre e cobre. Os teores foliares de boro apresentaram comportamento quadrático, diminuindo com o aumento das doses de ácido silícico e aumentando a partir da dose de $4 \mathrm{~g} \mathrm{~kg}^{-1}$ de solo. Em microanálise de raio X, mudas de cafeeiro com cercosporiose apresentam menores picos de potássio e cálcio, independente da cultivar utilizada.

PALAVRAS-CHAVE: Coffea arabica, Cercospora coffeicola, ácido silícico, silicato de cálcio, microanálise de raios- $X$.

\section{ABSTRACT}

EFFECT OF SILICON ON THE INTENSITY OF BROWN EYE SPOT AND ON THE MINERAL NUTRITION OF COFFEE SEEDLINGS. Our objective was to verify the effect of silicon on the intensity of brown eye spot and on the mineral nutrition of coffee seedlings. In the first experiment, 6 doses of silicic acid $\left(0,0.5,1,2,4\right.$ and $6 \mathrm{~g} \mathrm{~kg}^{-1}$ soil) were tested using a complete randomized block design with 4 replicates with 6 coffee seedlings cultivar Catuaí Vermelho IAC 99 inoculated with the fungus Cercospora coffeicola. In the second experiment, X-ray microanalysis in a scanning electron microscope was performed on 2 coffee cultivars (Topazio MG1190 and Icatu Precoce IAC 3282), inoculated and non-inoculated with C. coffeicola, treated and untreated with calcium silicate $\left(1 \mathrm{~g} \mathrm{~kg}^{-1}\right.$ of soil). With the increase of the silicic acid doses, there was observed a reduction in the area under the disease progress curve of the number of lesions per leaf (AUPCNLL), coupled with a linear reduction in the foliar contents of magnesium and phosphorus as well as an increase in the contents of sulfur and copper. The foliar contents of boron presented a quadratic behavior, decreasing with the increase of silicic acid and increasing with the dose of $4 \mathrm{~g} \mathrm{~kg}^{-1}$ of soil. In X-ray microanalysis, coffee seedlings with brown eye spot presented lower peaks of potassium and calcium, regardless of the cultivar used.

KEY WORDS: Coffea arabica, Cercospora coffeicola, silicic acid, calcium silicate, X-ray microanalysis.

\section{INTRODUÇÃO}

O Estado de Minas Gerais é o maior produtor de café do Brasil, sendo responsável por $66,0 \%$ da produção nacional, com mais de três bilhões de pés plantados. Essa imensa área plantada passa pela formação de mudas, as quais devem ser de cultivares produtivas, bem adaptadas, vigorosas, livres de pragas e doenças para o sucesso do empreendimento. Sendo assim é significativa a produção de mudas de café no Estado, a qual foi estimada em 1,64 bilhões de mudas nos últimos anos (COMPANHIA..., 2009).

Dessa forma, o controle de doenças no viveiro é importante para produzir mudas de qualidade. Dentre as doenças responsáveis por perdas de mudas, encontra-se a cercosporiose (Cercospora

${ }^{2}$ Universidade Federal de Lavras, Departamento de Fitopatologia, Lavras, MG, Brasil.

${ }^{3}$ Universidade Federal de Lavras, Departamento de Ciência dos Solos, Lavras, MG, Brasil. 
coffeicola Berk. \& Cooke), responsável por intensa desfolha, atraso no crescimento e raquitismo das plantas (FERNANDEZ-BORRERO et al., 1966). De acordo com Pozza et al. (2001), a cercosporiose é a doença do cafeeiro com maior possibilidade de ser controlada com práticas culturais, podendo-se, em alguns casos, evitar o uso do controle químico. Dentre as práticas culturais recomendadas para o manejo da doença incluem: evitar umidade excessiva do substrato, excesso de insolação e, principalmente, adubação equilibrada do substrato, pois a cercosporiose é muito influenciada pelas condições nutricionais da planta (FERNANDES et al., 1991).

A relação entre nutrição mineral e o progresso da cercosporiose já foi estudada por alguns autores. A aplicação de nutrientes como cálcio, nitrogênio, fósforo podem reduzir a doença (GARCIA JÚNIOR et al., 2003; PozZA et al., 2001; FerNANDES, 1988). Já a adubação com potássio apresenta resultados controversos, sendo observada tanto redução (GARCIA JÚNIOR et al., 2003) quanto aumento da doença (Pozza et al., 2001). Além destes nutrientes, o silício, considerado como elemento benéfico ou útil para as plantas, tem se destacado na redução de doenças do cafeeiro. A adição de silicato de cálcio ao substrato $\left(1 \mathrm{~g} \mathrm{~kg}^{-1}\right.$ de substrato) de mudas de cafeeiro proporcionou a redução de $63,2 \%$ nas folhas lesionadas com $C$. coffeicola e de $43 \%$ no total de lesões por planta em comparação à testemunha sem adição de silicato (Pozza et al., 2004). AmAral et al. (2008) observaram que a aplicação de silicato de potássio, via foliar, em mudas de cafeeiro, resultou em decréscimo da área abaixo da curva de progresso da cercosporiose. Além do efeito da redução da doença, BotelHo et al. (2005) verificaram alteração na nutrição de mudas de cafeeiro quando adubadas, via solo, com silicato de cálcio e silicato de sódio. Os teores de nitrogênio, cálcio e manganês foram influenciados significativamente pela suplementação de silicato ao substrato.

A microanálise de raios-X (MAX) é uma técnica utilizada para avaliar o efeito do silício na resistência deplantas a doenças (Luxetal., 2002). PozzAetal.(2004) observaram, com o uso da MAX, a presença de Si em mudas de cafeeiro adubadas com silicato de cálcio.

Contudo, os estudos realizados com silício no controle de doenças do cafeeiro utilizaram como fonte deste nutriente silicatos que possuem em sua composição, cálcio e potássio, nutrientes com influência no progresso de doenças (MARSCHNER, 1995). $\mathrm{O}$ ácido silícico $\left(\mathrm{H}_{4} \mathrm{SiO}_{4}\right)$ é uma fonte pura de silício que possibilita o estudo do seu efeito isoladamente no controle da cercosporiose do cafeeiro.

Com base nessas informações, este trabalho teve por objetivos verificar o efeito de doses de ácido silícico na intensidade da cercosporiose em mudas de cafeeiro cultivar Catuaí Vermelho IAC 99, avaliar o efeito do ácido silícico na nutrição mineral das mu- das de cafeeiro e verificar, com uso da microanálise de raios $X$, a presença de nutrientes nas cultivares de cafeeiro Icatu Precoce 3282 e Topázio MG1190, tratadas e não tratadas com silicato de cálcio, com e sem sintomas de cercosporiose.

\section{MATERIAL E MÉTODOS}

Experimento 1- Influência de doses de ácido silícico na intensidade da cercosporiose e na nutrição mineral de mudas de cafeeiro

O ensaio foi conduzido em casa de vegetação do Departamento de Fitopatologia (DFP), na Universidade Federal de Lavras (UFLA), no período de setembro de 2005 a maio de 2006 . O delineamento experimental utilizado foi em blocos casualizados, com 4 repetições. Foram aplicadas, no solo, seis doses de ácido silícico (Sigma®): 0; 0,5; 1; 2; 4 e $6 \mathrm{~g} \mathrm{~kg}^{-1}$ de solo. A parcela experimental foi constituída por seis mudas de cafeeiro.

Sementes de cafeeiro da cultivar Catuaí Vermelho IAC 99 foram semeadas em bandejas de plástico com areia autoclavada e diariamente irrigadas até atingirem o estádio orelha-de-onça. Posteriormente, foram repicadas para sacos de polietileno $(15 \times 20 \mathrm{~cm})$ contendo Latossolo Vermelho Típico com 13,6 mg $\mathrm{dm}^{-3}$ de Si. Foram adicionadas ao solo as seguintes doses de ácido silícico: 0; 0,5; 1,0; 2,0; 4,0 e 6,0 g do produto por $\mathrm{kg}$ de solo. $\mathrm{O}$ solo foi irrigado com água destilada até atingir a capacidade de campo e permaneceu reagindo por 20 dias. Após o período de incubação, os teores de Si no solo foram novamente quantificados apresentando os valores de: 14,7;17,1; 19,$1 ; 33,0$ e $68 \mathrm{mg} \mathrm{dm}^{-3}$ de $\mathrm{Si}$, para as doses de 0,$5 ; 1$; 2; 4 e 6 g de ácido silícico, respectivamente.

Foi realizada adubação com: $300 \mathrm{mg} \cdot \mathrm{dm}^{-3}$ de nitrogênio $(\mathrm{N}), 300 \mathrm{mg} \cdot \mathrm{dm}^{-3}$ de potássio $(\mathrm{K}), 200$ $\mathrm{mg} \cdot \mathrm{dm}^{-3}$ de fósforo $(\mathrm{P}), 30 \mathrm{mg} \cdot \mathrm{dm}^{-3}$ de magnésio $(\mathrm{Mg})$, $50 \mathrm{mg} \cdot \mathrm{dm}^{-3}$ de enxofre (S), $0,5 \mathrm{mg} \cdot \mathrm{dm}^{-3}$ de boro (B), $1,5 \mathrm{mg} \cdot \mathrm{dm}^{-3}$ de cobre $(\mathrm{Cu}), 3,0 \mathrm{mg} \cdot \mathrm{dm}^{-3}$ de manganês (Mn), 0,1 mg.dm ${ }^{-3}$ de molibdênio (Mo) e 5,0 mg.dm ${ }^{-3}$ de zinco (Zn). O cálculo da necessidade de calagem (NC) baseou-se na análise química prévia do solo, visando atingir uma saturação por bases de $50 \%$ conforme recomendado por GUIMARÃEs et al. (1999).

Durante todo o período de condução do experimento, a irrigação das mudas foi realizada somente com água destilada, visando evitar adição de silício na testemunha.

Ao atingirem três pares de folhas definitivas, as mudas de cafeeiro foram inoculadas com a suspensão de 1,5 × $10^{4}$ conídios $/ \mathrm{mL}$, segundo metodologia utilizada por Pereira et al. (2008).

A avaliação da incidência e da severidade da cercosporiose nas mudas de cafeeiro foi realizada 
semanalmente, em todas as seis plantas da parcela, totalizando cinco avaliações. A incidência foi determinada pela porcentagem do número de plantas com sintomas na parcela e pelo número de folhas com lesão/planta. A severidade da cercosporiose foi quantificada pelo número de lesões/folha e pela escala diagramática proposta por FERNANDES (1988). Os índices médios de incidência e severidade observados foram transformados em área abaixo da curva de progresso da doença (AACPD), de acordo com SHANER; FINNEY (1977).

Aárea foliar total decada parcela foi determinada ao final do experimento, com o medidor laser de área foliar (Laser Área Meter Cl 203- CID Incorp.). A área foliar específica foi quantificada pela razão área foliar/ peso foliar seco. Já a \% desfolha foi determinada pela contagem do número de folhas caídas (NFC)*100/ número total de folhas (NTF).

Após o término das avaliações da doença, da área foliar e da porcentagem de desfolha, a parte aérea e as raízes das plantas foram lavadas em água destilada, acondicionadas, separadamente, em sacos de papel e colocadas em estufa, a $60^{\circ} \mathrm{C}$, até atingirem peso constante. Realizou-se a pesagem do material para a determinação do peso seco da parte aérea e de raiz das plantas de cada tratamento. Em seguida, o material foi moído para a realização das análises nutricionais foliares de macronutrientes, micronutrientes e silício. A determinação dos teores de nitrogênio $(\mathrm{N})$, fósforo $(\mathrm{P})$, potássio $(\mathrm{K})$, cálcio $(\mathrm{Ca})$, magnésio $(\mathrm{Mg})$, enxofre $(\mathrm{S})$, boro $(\mathrm{B})$, cobre $(\mathrm{Cu})$, ferro $(\mathrm{Fe})$, manganês $(\mathrm{Mn})$ e zinco $(\mathrm{Zn})$ foram realizadas no Laboratório de Análise Foliar do Departamento de Química da UFLA, de acordo com metodologia proposta por Malavolta et al.(1997). Para a quantificação de silício nas folhas utilizou-se a metodologia proposta por RodRIGUEs et al. (2003).

A análise estatística do experimento foi realizada coma utilização do programaSisvar, versão 4.6(Build 6.1), do qual foram obtidas a análise de variância, a análise de regressão e os ajustes de modelos, cujos resultados foram significativos no teste $\mathrm{F}$, considerando uma significância de 5\%.

Experimento 2- Microanálise de raios X (Max) da superfície de folhas de cultivares de cafeeiro inoculadas com C. coffeicola

O experimento foi conduzido em delineamento experimental em blocos casualizados e a análise de variância em esquema fatorial $2 \times 2 \times 2$, sendo adição de silicato de cálcio ao substrato de plantio (com e sem Si), doença (inoculada e não inoculada) e cultivares de cafeeiro (Icatu Precoce IAC 3282 e Topázio MG1190) com quatro repetições. As parcelas experimentais foram constituídas por quatro plantas. Nas parcelas do tratamento com silicato de cálcio ( $23 \% \mathrm{CaO}$ e $63 \%$ de $\left.\mathrm{SiO}_{2}\right)$ foi misturado $1 \mathrm{~g}$ do produto por quilo de substrato antes do plantio das mudas. A dose $1 \mathrm{~g}$ foi escolhida por ter proporcionado redução na intensidade da cercosporiose em mudas de cafeeiro em trabalhos conduzidos por Pozza et al. (2004) e BotelHo et al. (2005).

Sementes de cafeeiro das cultivares Icatu e Topázio foram colocadas em bandejas de plástico com areia autoclavada, sendo diariamente irrigadas. Ao atingirem o estádio orelha-de-onça, foram transplantadas para saquinhos de polietileno $(11 \mathrm{x}$ $20 \mathrm{~cm}$ ), os quais continham o seguinte substrato: $70 \%$ de esterco bovino curtido, $30 \%$ de terra de subsolo, 5 $\mathrm{kg}$ de superfosfato simples $/ \mathrm{m}^{3}$ de substrato e $0,5 \mathrm{~kg}$ de cloreto de potássio/ $\mathrm{m}^{3}$ de substrato (GUIMARÃES et al., 1999).

Ao atingirem três pares de folhas definitivas, as mudas de cafeeiro foram inoculadas com a suspensão de $1,5 \times 10^{4}$ conídios $/ \mathrm{mL}$, segundo metodologia utilizada por PEREIRA et al. (2008). A coleta das folhas de cafeeiro para realização da microanálise de raios $\mathrm{X}(\mathrm{MAX})$ ocorreu quando sintomas da cercosporiose apareceram.

Para a microanálise de raios- $X$ (MAX), foram consideradas, como amostras, folhas retiradas do terceiro par do ramo ortotrópico, contadas partindo do ápice para a base, das plantas da parcela. De cada folha amostrada, foram retirados dois fragmentos do limbo foliar ( $9 \mathrm{~mm}^{2}$ cada). Posteriormente, os espécimes foram montados em suportes de alumínio "stubs", com metade destes montados com a face superior voltada para cima e a outra metade com a face inferior voltada para cima. Após esse procedimento, esses espécimes foram levados para o dessecador contendo sílica gel, onde permaneceram por 24 horas. Em seguida, foram levados ao aparelho 'sputtering' (MED 010, Balzer) e cobertos com uma fina camada de carbono. Em seguida, as amostras foram observadas em MEV (DSM940-Zeiss, acoplado ao sistema de MAX: EDS-Oxford Instrument Link ISIS) no Núcleo de Apoio à Pesquisa/Microscopia Eletrônica Aplicada à Agricultura na Escola Superior de Agricultura "Luiz de Queiroz" (NAP/MEPA ESALQ-USP), onde foram avaliados os elementos presentes na superfície das folhas.

\section{RESULTADOS E DISCUSSÃO}

A área abaixo da curva de progresso da incidência (AACPI), área abaixo da curva de progresso da severidade (AACPS) e a área abaixo da curva de progresso do número de folhas lesionadas por planta (AACPNFL) não diferiram significativamente coma adição de doses crescentes deácido silícico ao solo de plantio. No entanto, observou-se decréscimo linear na área abaixo da curva de progresso do número de 
lesões / folha (AACPNLF) com o aumento das doses deSiao solo, com redução de $29,5 \%$ da menor $\left(0 \mathrm{~g} \mathrm{~kg}^{-1}\right)$ para a maior $\left(6 \mathrm{~g} \mathrm{~kg}^{-1}\right)$ dose de ácido silícico (Fig. 1).

Resultados semelhantes foram observados por Pozza et al. (2004) em que mudas de cafeeiro cultivar Catuaí Vermelho IAC 99, adubadas com silicato de cálcio no solo ( $1 \mathrm{~g} \mathrm{~kg}^{-1}$ de substrato) e inoculadas com C. coffeicola, apresentaram redução de $63,2 \%$ nas folhas lesionadas e de $43 \%$ no total de lesões por planta, quando comparadas à testemunha. Foi também observada, com uso de microscopia eletrônica de varredura, a presença de cutícula mais espessa coma camada de cera epicuticular mais desenvolvida nos tratamentos com adição de silicato, o que pode explicar em grande parte, de acordo com os autores, a redução no número de lesões de $C$. coffeicola.

Amaral et al. (2008), também estudando o patossistema cafeeiro C. coffeicola, observaram que a aplicação de silicato de potássio via foliar proporcionou decréscimo de $47 \%$ na área abaixo da curva de progresso da doença (AACPD) em mudas e de $31 \%$ em plantas adultas no campo.

A área foliar, a área foliar específica, a porcentagem de desfolha e o peso da matéria seca da parte aérea e do sistema radicular das mudas de cafeeiro não diferiram com os tratamentos testados.

A adição de doses crescentes de ácido silícico ao solo de plantio não alterou os teores foliares de silício nas mudas de cafeeiro. ReIs et al. (2008), estudando o efeito da associação de silício liquido solúvel com fungicida no controle fitossanitário do cafeeiro, também não encontraram diferenças nos teores foliares de Si das plantas tratadas com silício. Este resultado pode ser explicado pelo fato de que o acúmulo de silício nas plantas ser controlado pela capacidade das raízes absorverem $\mathrm{Si}$ e as espécies vegetais se diferenciam quanto à absorção deste elemento (MA; Y AMAJI, 2006). Desta forma, possivelmente o cafeeiro apresente absorção reduzida de $\mathrm{Si}$, não alterando teores foliares mesmo com a aplicação de doses crescentes de ácido silícico.

Com relação às análises foliares de macro e micronutrientes, os teores de fósforo $(\mathrm{P})$, magnésio $(\mathrm{Mg})$, enxofre $(\mathrm{S})$, boro $(\mathrm{B})$ e cobre $(\mathrm{Cu})$ apresentaram variações com os tratamentos testados (Fig. 2). Os teores foliares de fósforo e de magnésio decresceram linearmente com aumento das doses deácido silícico adicionadas ao solo de plantio de mudas de cafeeiro. De acordo com ToKURA et al. (2007), o efeito do silício no crescimento vegetal parece estar associado com as reações desse elemento com o P no solo e na planta. A similaridade química de duas formas aniônicas de $\mathrm{PeSi}, \mathrm{H}_{2} \mathrm{PO}_{4}{ }^{-} \mathrm{eH}_{3} \mathrm{SiO}_{4}$, é grandemente responsável por isto.

Observou-seaumento linear nos teores de enxofre ecobrenas plantas, com o aumento das doses deácido silícico. Para os teores foliares de boro, observou-se comportamento quadrático, apresentando redução à medida que se aumentou as doses de ácido silícico e, a partir da dose $4 \mathrm{~g}$, observou-se aumento nos teores deste nutriente. SILVA; BOHNEN (2003) relataram diferenças no acúmulo de fósforo, ferro, manganês, boro e cálcio em plantas de arroz tratadas com Si. Provavelmente, as alterações observadas nos teores foliares de boro, cobre, enxofre, magnésio e fósforo por reações no solo do Si com tais nutrientes, pois de acordo com MATICHENKOV et al. (1995) o ácido silicico tem um efeito significativo na textura do solo, capacidade de retenção deágua, capacidade de adsorção, a erosão do solo e de estabilidade.

As cultivares de cafeeiro estudadas, Icatu e Topázio, não apresentaram picos de $\mathrm{Si}$, mesmo com a suplementação de $1 \mathrm{~g}$ de silicato de cálcio no substrato (Fig. 3 A, C e E, G, respectivamente). Resultados contrários foram encontrados por PozzA et al. (2004), onde picos de Si foram observados com auxilio da microanálise de raios- $X$ em cultivares de cafeeiro (Catuaí, Mundo Novo e Icatu) adubadas com $1 \mathrm{~g}$ de silicato de cálcio aplicado via solo. $\mathrm{O}$ tempo de condução de experimento pode ter influenciado o resultado, pois, no presente trabalho, as mudas estavam com, aproximadamente, quatro meses quando foi realizada a microanálise de raios X, enquanto Pozza et al. (2004) realizaram a mesma análise com mudas de sete meses de idade.

Picos mais elevados de potássio e de cálcio foram observados em folhas de plantas sadias, (Fig. 3 C, De $\mathrm{G}, \mathrm{H})$ que nas folhas com sintomas da cercosporiose (Fig. 3 A ,B e E, F) independente da adição de silicato de cálcio ao substrato, tanto na cultivar Icatu quanto na Topázio. Resultados semelhantes, utilizando a técnica de microanálise de raios- $X$, foram relatados por Pozza et al. (2004), onde mudas de cafeeiro inoculadas com C. coffeicola apresentaram baixos picos de cálcio e potássio.

O modo de ação do silício na resistência de plantas a doenças não está totalmente esclarecido. Primeiramente, acreditava-se que a ação do silício na supressão de doenças era devido à barreira física formada pela polimerização do Si na parede celular (FAuteux et al., 2005). Contudo, trabalhos recentes (RodRigues et al., 2004; Resende et al., 2009) relatam a possibilidade do efeito do Si na supressão de doenças em plantas, ser ativo, provavelmente, devido a indução de sinais para reações de defesa da planta.

No presente trabalho a redução da AACPNL pode ter ocorrido provavelmente devido a ativação de respostas de defesa da própria planta que se encontravam latentes. A ação do silício na ativação de respostas de defesa, como proteínas relacionadas à patogênese e lignificação, foi relatada em cafeeiro contra patógenos em alguns trabalhos. Amaral et al. (2008), em experimento com mudas de cafeeiro cultivar Mundo Novo, observaram proteção contra 
C. coffeicolla e relataram que parte desta proteção conferida pelo silicato de potássio pode ser explicada pelo aumento nas atividades de enzimas de defesa como as peroxidases, polifenoloxidases e o maior acúmulo de lignina. SiLva et al. (2010) concluíram que o fornecimento de silicato de cálcio no substrato de mudas de cafeeiro aumenta a resistência das raízes contra Meloidogyne exigua, diminuindo sua capacidade reprodutiva. Estes autores observaram
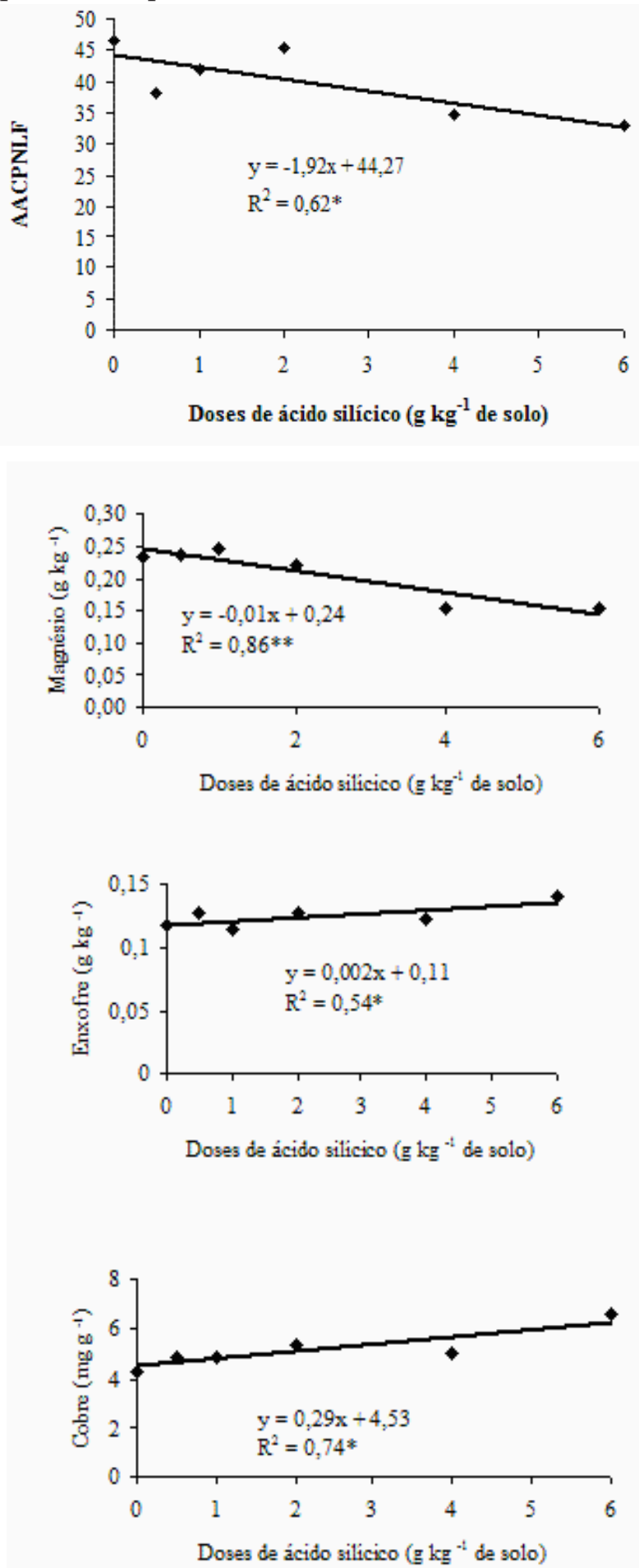

aumento de $11,5 \%$ nos teores de lignina nas raízes das plantas inoculadas com M. exigua da cultivar Catuaí 44 (suscetível) supridas com silicato de cálcio e de $23 \%$ nas raízes da cultivar IAPAR 59 (resistente). Observaram também aumento na atividade das enzimas peroxidases, polifenoloxidases e fenilalanina amônia liase nas raízes das plantas aos 10 dias após a inoculação com este nematóide nas cultivares Catuaí 44 e IAPAR 59.

Fig. 1 - Área abaixo da curva de progresso do número de lesões de cercosporiose por folha (AACPNLF) de mudas de cafeeiro cultivar Catuaí Vermelho IAC 99 em função das doses de ácido silícico aplicadas via solo.
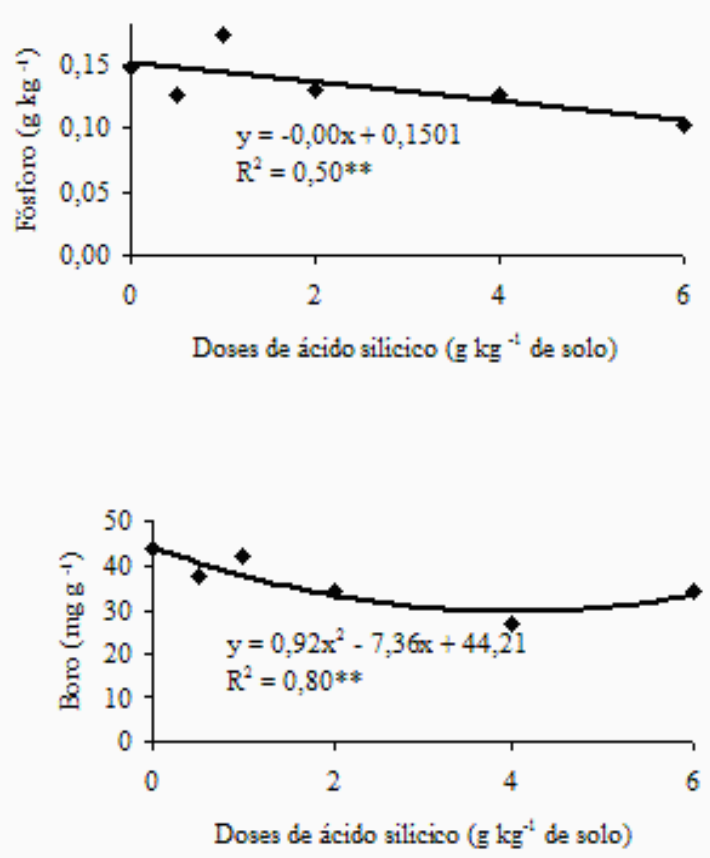

Fig. 2 - Teores foliares de fósforo $(\mathrm{P})$, magnésio $(\mathrm{Mg})$, enxofre $(\mathrm{S})$, boro $(\mathrm{B})$ e cobre $(\mathrm{Cu})$ de mudas de cafeeiro cultivar Catuaí Vermelho IAC 99 em função das doses de ácido silícico aplicadas via solo. 

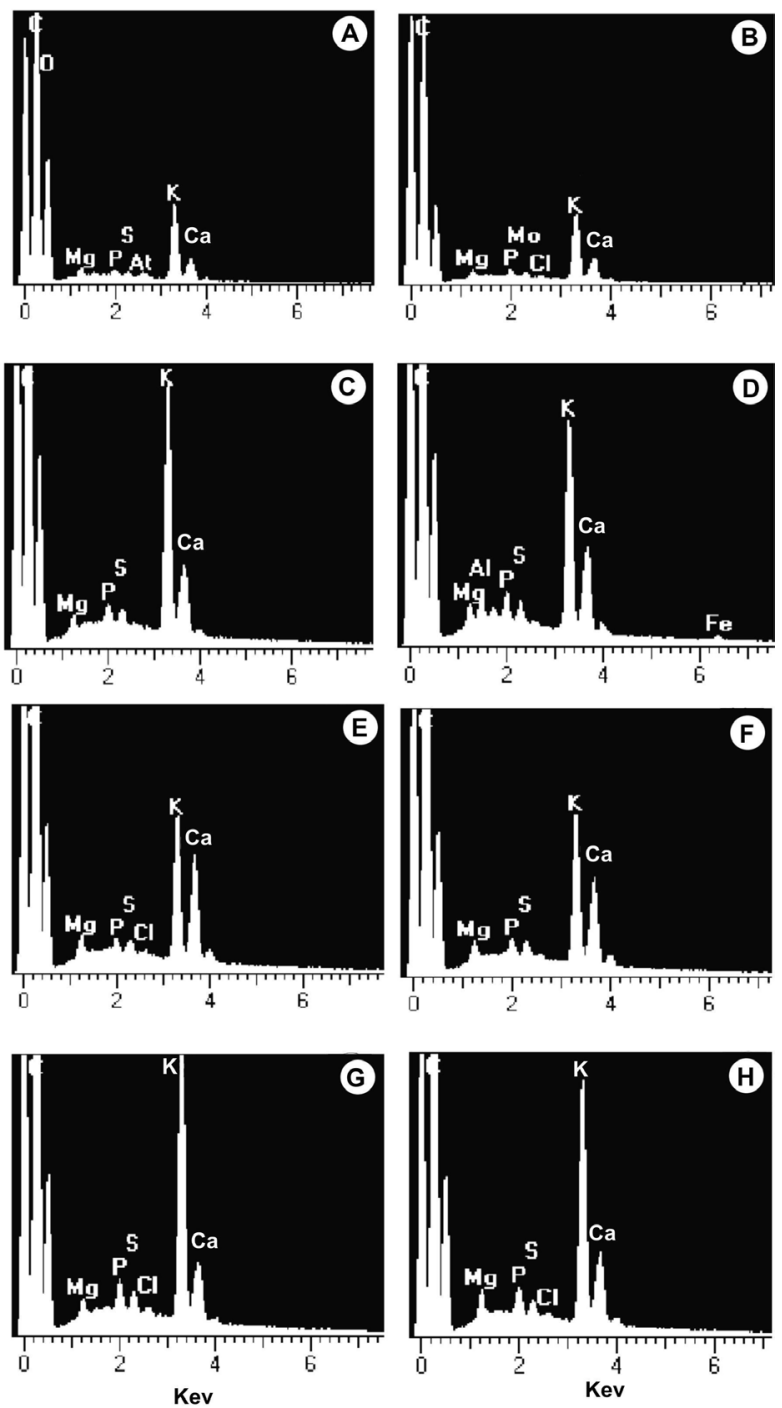

\section{CONCLUSÕES}

O ácido silícico reduz a severidade da cercosporiose em mudas de cafeeiro.

A adubação com ácido silícico em mudas de cafeeiro não altera os níveis de silício das folhas, mas pode aumentar os teores foliares de enxofre e cobre e reduzir os teores foliares de magnésio e fósforo.

Mudas de cafeeiro, adubadas com silicato de cálcio e com sintomas da cercosporiose apresentam menores picos de potássio e cálcio independente da cultivar utilizada.

\section{REFERÊNCIAS}

AMARAL, D.R.; RESENDE, M.L.V.; RIBEIRO JÚNIOR, P.M.; BOREL, J.C.; MAC LEOD, R.E.O.; PÁDUA, M.A. Silicato de potássio na proteção do cafeeiro contra Cercospora coffeicola. Fitopatologia Brasileira, v.33, p.425-431, 2008.
Fig. 3 - Microanálise de raios X de folhas cafeeiro (Coffea arabica L.) cultivar Icatu IAC 3282 adubadas com $\mathrm{CaSiO}_{3}$ - Si (A e C) e não adubadas (B e D), folhas inoculadas com C. coffeicola - Cc (A e B) e folhas sadias (C e D). Cultivar Topázio MG1190 com $\mathrm{CaSiO}_{3}(\mathrm{E} \mathrm{e} \mathrm{G})$ e sem $\mathrm{CaSiO}_{3}(\mathrm{~F} \mathrm{e} \mathrm{H})$, folhas inoculadas com $C$. coffeicola (E e F) e folhas sadias ( $\mathrm{G}$ e H). A adubação foi realizada com $1 \mathrm{~g}$ de $\mathrm{CaSiO}_{3}$ por kg de substrato. Escala dos gráficos: Total na vertical 5 cps (Capturas por Segundo).
BOTELHO, D.M.S. dos; POZZA, E.A.; POZZA, A.A.A.; CARVALHO, J.G. de; BOTELHO, C.E.; SOUZA, P.E. Intensidade da cercosporiose em mudas de cafeeiro em função de fontes e doses de silício. Fitopatologia Brasileira, v.30, n.6, p.582-588, 2005.

\section{COMPANHIA NACIONAL DE ABASTECIMENTO.}

(Brasil). Levantamento de café. Disponível em:< http:/ / www.conab.gov.br/conabweb>. Acesso em: 10 mai. 2009.

FAUTEUX, F.; BOREL-RÉMUS, W.; MENZIES, J. G.; BÉLANGER, R. R. Silicon and plant disease resistance against pathogenic fungi. FEMS Microbiology Letters, v.249, n.1, p.1-6, 2005.

FERNANDES, C. D. Efeito de fatores do ambiente e da concentração de inóculo sobre a Cercosporiose do cafeeiro. 1988. 73p. Dissertação (Mestrado em Fitopatologia) - Universidade Federal de Viçosa, Viçosa, MG, 1988.

FERNANDES, C.D. ; PELOSO ; MAFFIA, L.A. ; VALE, R.; ZAMBOLIM, L. Influência da concentração de ino- 
culo de Cercospora coffeicola e do período de molhamento foliar na intensidade da cercosporiose do cafeeiro. Fitopatologia Brasileira, v.16, n.1, p.39-43, 1991.

FERNANDEZ-BORRERO, O.; MESTRE, A.M.; DUQUE, S.L. Efecto de la fertilizacion en la incidência de la mancha de hierro (Cercospora coffeicola) en frutos de café. Cenicafé, v.17, n.1, p.5-16, 1966.

GARCIA JÚNIOR, D.; POZZA, E. A.; POZZA, A. A. A.; SOUZA, P. E.; CARVALHO, J. G.; BALIEIRO, A. C. Incidência e severidade da cercosporiose do cafeeiro em função do suprimento de potássio e cálcio em solução nutritiva. Fitopatologia Brasileira, v.28, n.3, p.286-291, 2003.

GUIMARÃES, P.T.G.; GARCIA, A.W.R.; VENEGAS, V.H.A.; PREZOTTI, L.C.; VIANA, A.S.; MIGUEL, A.S.; MALAVOLTA, E.; CORREA, J.B.; LOPES, A.S.; NOGUEIRA, F.D.; MONTEIRO, A.V.C.; OLIVEIRA, J.A. Cafeeiro In: RIBEIRO, A.C.; GUIMARÃES, P.T.G.; ALVAREZ, V.V.H. (Ed.). Recomendações para uso de corretivos e fertilizantes em Minas Gerais: $5^{a}$ aproximação. Viçosa: Comissão de Fertilidade do Solo do Estado de Minas Gerais, 1999. p.289-302.

LUX. A.; LUXOVA, M.; HATTORI, T.; INANAGA, S.; SUGIMOTO, Y. Silicification in sorghum (Sorghum bicolor) cultivars with different drought tolerance. Physiologic Plantarum, v.115, p.87-92, 2002.

MA, J.F.; YAMAJI, N. Silicon uptake and accumulation in higher plants. Trends in Plant Science, v.11, n.8, p.392397, 2006.

MALAVOLTA, E.; VITTI, G.C.; OLIVEIRA S.A. Avaliação do estado nutricional das plantas: princípios e aplicações. 2.ed. Piracicaba: Associação Brasileira para Pesquisa do Fosfato, 1997. 238p.

MARSCHNER, H. Mineral nutrition of higher plants. 2.ed. London: Academic Press, 1995. 889p.

MATICHENKOV, V.V.; PINSKY, D.L.; BOCHARNIKOVA, E.A. Influence of mechanical compaction of soils on the state and form of available silicon. Eurasian Soil Science, v.27, n.12, p.58-67, 1995.

PEREIRA, R.B.; ALVES, E.; RIBEIRO JÚNIOR, P.M.; RESENDE, M.L.V. de.; LUCAS, G.C.; FERREIRA, J.B. Extrato de casca de café, óleo essencial de tomilho e acibenzolar-S-metil no manejo da cercosporiose-docafeeiro. Pesquisa Agropecuária Brasileira, v.43, n.10, p.1287-1296, 2008.

POZZA, A.A.A.; MARTINEZ, H.E.P.; CAIXETA, S.L.; CARDOSO, A.A.; ZAMBOLIM, L.; POZZA, E.A. Influência da nutrição mineral na intensidade da mancha de olho pardo em mudas de cafeeiro. Pesquisa Agropecuária Brasileira, v.36, n.1, p.53-60, 2001.

POZZA, A.A.A.; ALVES, E.; POZZA, E.A.; CARVALHO, J.G. de; MONTANARI, M.; GUIMARÃES, P.T.G.; SANTOS, D.M. Efeito do silício no controle da cercosporiose em três variedades de cafeeiro. Fitopatologia Brasileira, v.29, n.2, p.185-188, 2004.

REIS, T.H.P.; FIGUEIREDO, F.C.; GUIMARÃES, P.T.G.; BOTREL, P.P.; RODRIGUES, C.R. Efeito da associação silício líquido solúvel com fungicida no controle fitossanitário do cafeeiro. Coffee Science, v.3, n.1, p.76-80, 2008.

RESENDE, R.S.; RODRIGUES, F.A.; SOARES, J.M.; CASELA, C.R. Influence of silicon on some components of resistance to anthracnose in susceptible and resistant sorghum lines. European Journal of Plant Pathology, v.124, p.533-541, 2009.

RODRIGUES, F.A.; VALE F.X.R.; KORNDÖRFER, G.H.; PRABHU, A.S.; DATNOFF, L.E.; OLIVEIRA, A.M.A.; ZAMBOLIM, L. Influence of silicon on sheath blight of rice in Brazil. Crop Protection, v.22, n.1, p.23-29, 2003.

RODRIGUES, F.A.; MCNALLY, D.J.; DATNOFF, L.E.; JONES, J.B.; LABBÉ, C.; BENHAMOU, N.; MENZIES, J.G.; BÉLANGER, R. R. Silicon enhances the accumulation of diterpenoid phytoalexins in rice: a potencial mechanism for blast resistance. Phytopathology, v.94, n.2, p.177-183, 2004.

SHANER, G.; FINNEY, R.E. The effect of nitrogen $\mathrm{f}$ ertilization on the expression of slow-mildewing resistance in knox wheat. Phytopathology, v.70, n.8, p.1183-1186, 1977.

SILVA, L.S.; BOHNEN, H. Produtividade e absorção de nutrientes pelo arroz cultivado em solução nutritiva com diferentes níveis de silício e cálcio. Revista Brasileira de Agrociência, v.9, n.1, p.49-52, 2003.

SILVA, R.V.; OLIVEIRA, R.D.L.; NASCIMENTO, K.J.T.; RODRIGUES, F.A. Biochemical responses of coffee resistance against Meloidogyne exigua mediated by silicon. Plant Pathology, v.59, n.3, p.586-593, 2010.

TOKURA, A.M.; FURTINI NETO, A.E.; CURI, N.; CARNEIRO, L.F.; ALOVISI, A.A. Silício e fósforo em diferentes solos cultivados com arroz de cultivados sequeiro. Acta Scientiarum Agronomy, v.29, n.1, p.9-16, 2007.

Recebido em $12 / 1 / 10$

Aceito em 8/12/10 